\title{
La secesión de los ricos. Antonio Ariño y Juan Romero.
}

\section{Barcelona: Galaxia Gutenberg, 2016}

\section{Luis Moreno}

Instituto de Políticas y Bienes Públicos (CSIC)

luis.moreno@csic.es
El título del libro podría llamar a equívoco. Los autores, catedráticos de sociología y geografía humana respectivamente en la Universidad de Valencia, clarifican su idea del secesionismo plutocrático en el inicio de este volumen pletórico de ideas y sugerencias. No debería identificarse la desconexión de pudientes y acaudalados como la tercera opción 'salida' (exit) de las propuestas por Albert Hirschman (1970). Recuérdese que las otras dos alternativas confrontadas por los miembros de empresas 0 estados en situación de crisis 0 desasosiego son: 'voz' (voice) y 'lealtad' (loyalty). En la exposición de dicha tríada, el científico social norteamericano criticaba las teorías neoclásicas del comportamiento económico basado en la elección racional según los análisis de su influyente colega Mancur Olson (1965). № es, pues, la secesión de élites y ricos una 'salida'.

Los autores puntualizan, por tanto, que se trata de una independencia relativa del segmento rico que persigue sostener su posición de ventaja estando fuera - pero también dentro- del conjunto social, y con el propósito de exprimirlo a conveniencia sin implicarse en los costes de la voluntad general. Algunos ejemplos individuales de tal comportamiento gorrón e interesado (free riding) se ilustran con la de aquellos deportistas de gran predicamento y fama sociales por sus éxitos deportivos, pero con sus cuentas bancarias en Andorra o Panamá. Buscan con ello beneficiarse de un trato fiscal más ventajoso para sus fortunas del que obtendrían en los países que representan. Es el ventajismo del patriotismo libre de impuestos.

Trasluce en tales conductas autointeresadas la convicción, ya expresada por Margaret Thatcher, de que en nuestros tiempos y nuestras sociedades "no hay alternativa" (there's no alternative) respecto al modelo de globalización neoliberal y de avidez individualista. Según tal visión, la ósmosis contaminante del capitalismo de 'casino' característico del modelo remercantilizador anglo-norteamericano sería el motor del crecimiento mundial mediante la maximización de la economía de 'goteo' (trickle down economics) propiciada por los superricos. El enfoque característico de tal visión ha abogado por permitir las ayudas públicas a los más ricos y a la alta clase empresarial (facilitándoles una sustancial reducción impositiva). Al así hacerlo, se estimularía su implicación en el progreso económico a través de sus inversiones generadoras de prosperidad para todo el conjunto social. Sucede que, en realidad, se han agrandado exponencialmente la desigualdad y el déficit fiscal. En EE UU, por ejemplo, los ciudadanos menos gravados prefirieron invertir en el sector especulativo financiero, rehuyendo otros dominios de la economía productiva creadores, por ejemplo, de empleo y, por ende, de demanda agregada. Recuérdese que durante el primer mandato de Bill Clinton (1993-97), cuando los muy ricos pagaban casi el doble de impuestos que tras la crisis de 2007-08, se crearon 11,5 millones de puestos de trabajo, lo que se compara con la caída del empleo durante el período de "vacaciones fiscales' de George W. Bush. El desempleo se duplicó en el período desde el final de la presidencia de Clinton (2001) a la conclusión de la de Bush (2009) alcanzando el $8 \%$ de la población activa laboral.

En contraste con el concepto de economía productiva, el cual compete a todas aquellas actividades de producción de bienes o servicios, la economía especulativa, algo más compleja de definir, se concentra en la capacidad de facilitar rentabilidades dinerarias a partir de otro producto 
0 activo. La economía financiera sin regulación ha pasado, de tal manera, a estar dominada por los intereses de inversores y rentistas. Nuestro mundo se ha financiarizado irremisiblemente. Recuérdese que la financiarización generalizada en el Reino Unido y EE UU desde los años 1980 fue uno de los procesos determinantes de la eclosión de la ingeniería financiera causante del crack de 2007-08. Ya en 1986, las políticas de Thatcher impulsaron los mercados de valores e hicieron de la City londinense el Shangri-la de la desregulación con la eclosión de productos financieros opacos, luego adoptada con mayor ahínco, si cabe, por Wall Street durante el largo período de Alan Greenspan al frente de la Reserva Federal estadounidense (1987-2006). La conversión de los ciudadanos en inversores ha sido uno de los procesos más paradójicos - y no suficientemente analizados - en la eclosión de productos financieros en los mercados bursátiles (derivados y titulaciones). La falta de regulación de éstos últimos, la opacidad de las operaciones y la actuación criminal de los responsables de las corporaciones financieras que los gestionaban, fueron determinantes en la génesis de la 'crisis interminable' tras 2007-08.

Hoy el neoliberalismo irrestricto y resiliente sigue sustentándose en un axioma instrumental gráficamente expresado en 2014 por John Osborne, a la sazón ministro de Economía (Chancellor of Exchequer) en el gobierno conservador de David Cameron: "En la economía moderna global, donde se pueden cambiar de lugar las inversiones apretando un botón, y donde las empresas pueden trasladar empleos de un país a otro de la noche a la mañana, la economía de los impuestos altos son cosa del pasado". Los autores del libro son plenamente conscientes de los límites de las políticas 'soberanas' de los estados nación de corte westfaliano, los cuales siguen pugnando por mantener sus capacidades políticas y de poder con desigual fortuna. Muy oportunamente hacen mención del Mercadeo de Alta Frecuencia (High Fast Trading) que, en línea con la cita anterior de 0sborne, maximiza las oportunidades que ofrecen los algoritmos y operaciones en tiempo real de los grandes operadores de bolsa e intermediarios financieros.
El libro se divide en cuatro grandes partes. Tras un texto introductorio respecto al significado de la secesión elitaria, el segundo capítulo examina su agudización con la extensión de la 'crisis interminable'. Como no podía menos, Ariño y Romero inciden —y no poco — en el asunto de la desigualdad, cuya brecha ha crecido en nuestras democracias avanzadas de manera imparable y visiblemente obscena. Los autores se hacen eco del debate sobre los efectos de la disparidad de rentas a nivel mundial. Según ya hipotizaba Simon Kuznets (1955) con su famosa 'curva' en U invertida en los años 50 y 60 del pasado siglo, a medida que crecía la economía mundial las fuerzas del mercado provocarían primero un aumento de la desigualdad, pero luego ésta disminuiría posteriormente. Algo así parece demostrarse ahora con el aumento de rentas de las clases medias asiáticas y de economías emergentes tales como China, Corea o Taiwán, lo que ha producido una reducción de la desigualdad macroeconómica mundial. Ariño y Romero también hacen referencia al trabajo de Thomas Piketty (2014), el cual ha aportado datos y juicios en el debate de la desigualdad haciendo hincapié en que cuando la tasa de acumulación de capital aumenta más rápidamente que la economía, las disparidades de rentas se disparan. Sus estudios, de gran repercusión en el debate académico y mediático de los últimos tiempos, analizan en largas series históricas la concentración de la riqueza y su distribución durante los últimos 250 años.

Todo parece indicar que las tendencias favorables a la desigualdad serán difíciles de revertir, especialmente en lo que hace al caso de EE UU, donde persisten fuerzas poderosas que mantienen la desigualdad en un nivel alto. Considérese que entre 1970 al año 2012, el 1 \% más rico estadounidense ha incrementado su participación en la renta nacional del país norteamericano más del $150 \%$. Y es que el maridaje entre el mercado y el poder político, según lo señalado por Anthony Atkinson (2016), otro gran estudioso de la desigualdad económica y social, se hace cada vez más evidente. El creciente destino de los ingresos elevados (tanto del capital como del trabajo) va a manos de las mismas gentes, al igual que se intensifica la homo- 
gamia societaria (los educados y los ricos se juntan entre ellos). La economía también es política, una última convicción que, según Ariño y Romero, les ha impulsado a escribir el libro ahora recensionado.

En el caso de Europa, que ocupa la atención de la segunda parte del volumen, los profesores valencianos nos previenen también de las nuevas formas de la política del 'arramble'. Los resultados de la política del 'ganador todo se lleva' (winner-takesall politics) se plasmarían en una Europa asocial (Moreno, 2013) fundamentada moralmente en un individualismo remercantilizador, propulsor de una mayor disparidad de rentas y un reparto desigual de las cargas fiscales, tal y como ha venido sucediendo en EE UU según lo avanzado por Hacker y Pierson (2010). En no pocas coyunturas la creciente importancia del dinero en la política permite a los ricos fijar las reglas que les son favorables y mantener la dinámica de la desigualdad (Gilens, 2012).

Frente al capitalismo que beneficia el egoísmo de unos pocos, los autores reivindican el modelo del bienestar europeo. Pero son conscientes de las dificultades de superar el debate materialista de la desigualdad conformado por la máxima "tanto ganas, tanto vales". Ariño y Romero son sabedores de las dificultades de quebrar el "espejismo de la riqueza' de creciente predicamento en Europa y en España, ámbito analítico de la tercera parte del libro. Inciden, asimismo, en la paradoja que supone una cierta convergencia de España en los aspectos macro-estructurales del capitalismo financiero, pero también una divergencia con los países centrales continentales. Para los autores, la agenda neoliberal, hoy hegemónica, condiciona no sólo la tradicional soberanía de los estados, sino que empobrece la calidad de las democracias, genera precarización y destrucción de empleos, y limita los derechos de ciudadanía para grupos vulnerables.

Ante semejante situación de incertidumbre, inseguridad y repliegue en las sociedades afectadas - como la española - los autores se preguntan en el último capítulo del libro: ¿hay alternativas? En consonancia con su exposición en las páginas precedentes, los análisis normativos de la parte final del volumen se elaboran respecto a preguntas básicas tales como: ¿por qué elegimos la desigualdad?, ¿por qué aceptamos su legitimidad en sociedades democráticas? 0 ¿cómo se contribuye a permitir una situación insatisfactoria como la presente? En última instancia, permanece transversal en todas las intenciones de futuro el reto de cómo conseguir que los ciudadanos tengan capacidad de intimidación para que los ricos se vean obligados a compartir, evitando así su querencia secesionista.

Los autores abogan claramente por el hallazgo y la aplicación de medidas 'benignas' de política social que consoliden nuestros Estados del Bienestar, para así evitar factores 'malignos' alternativos que en el pasado auspiciaron perversamente una disminución de la desigualdad. Como ha señalado certeramente Branko Milanovi' c (2016), la historia nos enseña también que dichos factores malignos como las guerras - a su vez causadas por la búsqueda de las elites nacionales de nuevos territorios donde poder invertir y controlar políticamente (como ocurrió en la I Guerra Mundial)—, pueden contribuir a nivelar los ingresos por la vía de la destrucción, la muerte y el sufrimiento humano. Con la muy útil aportación de estudios cabales como los recogidos en este libro, quizá consigamos esquivar la vía destructiva hacia la igualdad en la pobreza y en la muerte, y podamos mantener y consolidar nuestro Modelo Social Europeo (MSE) articulado por valores de equidad social (igualdad), solidaridad colectiva (redistribución) y eficiencia productiva (logro).

Conviene no olvidar que el MSE promueve una ciudadanía social entendida como una limitación a la desigualdad social y económica, además de una mayor protección a los más vulnerables y un partenariado social activo. Como objetivo estratégico, el MSE auspicia el crecimiento económico sostenido y sostenible basado en la cohesión social favorecedora de la producción con valor añadido. La axiología de los europeos es el soporte legitimador de una Europa social que ha sido cuestionada abiertamente por la última crisis económica: ¿es ontológicamente posible un capitalismo del bienestar de la austeridad? La respuesta demanda una clarificación de los conceptos de gasto social, así como 
de la renovación efectiva del pacto social implícito en los sistemas de progresividad fiscal. Los autores certifican su vocación europeísta como recurso argumental para demandar más Europa y menos parroquialismo estatalista en el Viejo Continente.

Los lectores, tanto académicos como aquellos comúnmente interesados en la evolución de nuestras democracias, hallarán gran provecho y reflexión en las páginas de este volumen. La identificación de las áreas analíticas de mayor repercusión en los procesos examinados en el libro refleja no sólo un extenso bagaje de conocimientos de los asuntos tratados por parte de Ariño y Romero. Evidencia una cabal revisión bibliográfica y un aprovechamiento de no pocas discusiones complementarias a la redacción del libro. El objetivo final no podría ser otro que el de contribuir a una discusión ciudadana más amplia sobre la desigualdad, la secesión de los ricos o la expulsión de capas crecientes de la población a los márgenes del sistema. Todo ello refleja la pasión de los autores por los asuntos públicos y su pulsión por promocionar el bien común de los ciudadanos.

\section{BIBLIOGRAFÍA}

Atkinson, Anthony B. (2016), Inequality: What Can Be Done About It? Cambridge (MA): Harvard University Press.
Gilens Martin (2012), Affluence and Influence. Economic Inequality and Political Power in America. Princeton (NJ): Princeton University Press.

Hacker, Jacob S. y Pierson, Paul (2010), WinnerTake-All Politics: How Washington Made the Rich Richer and Turned Its Back on the Middle Class. Nueva York (NY): Simon \& Schuster.

Hirschman, Albert 0. (1970), Exit, Voice, and Loyalty: Responses to Decline in Firms, Organizations, and States. Cambridge (MA): Harvard University Press [Ed. castellano: Salida, voz y lealtad: respuestas al deterioro de empresas, organizaciones y estados. México D.F.: Fondo de Cultura Económica, 1977].

Kuznets, Simon (1955), 'Economic growth and income inequality', American Economic Review, XLV (1): 1-28.

Milanović, Branko (2016), Global Inequality. A New Approach for the Age of Globalization. Cambridge (MA): Harvard University Press.

Moreno, Luis (2013), La Europa asocial. Crisis y Estado del Bienestar. Barcelona: Península.

Olson, Mancur (1965), The Logic of Collective Action: Public Goods and the Theory of Groups. Cambridge (MA): Harvard University Press [Ed. castellano: La lógica de la acción colectiva: bienes públicos y la teoría de grupos. México, D.F.: Limusa, Noriega Editores, 1992].

Piketty, Thomas (2014), El capital en el siglo XXI. Madrid: Fondo de Cultura Económica de España. 